\title{
Effect of amitriptyline and pregabalin on heart rate variability and electrolytes in neurotrophic pain in diabetic patients
}

\author{
Rohan Srivastava $^{1 *}$, N. D. Kantharia ${ }^{2}$ \\ ${ }^{1}$ Department of Medicine, Breach Candy Hospital, Mumbai, Maharashtra, India \\ ${ }^{2}$ Department of Pharmacology, Government Medical College, Surat, Gujarat, India
}

Received: 17 November 2021

Revised: 13 December 2021

Accepted: 14 December 2021

\section{*Correspondence:}

Dr. Rohan Srivastava,

Email: drrohan3005@gmail.com

Copyright: (c) the author(s), publisher and licensee Medip Academy. This is an open-access article distributed under the terms of the Creative Commons Attribution Non-Commercial License, which permits unrestricted non-commercial use, distribution, and reproduction in any medium, provided the original work is properly cited.

\section{ABSTRACT}

Background: The data regarding effects of amitriptyline and pregabalin on heart rate variability in patients with neuropathic pain in diabetic patients are poorly understood in India. The present study was conducted to evaluate the effect of amitriptyline and pregabalin on heart rate variability in diabetic patients with neuropathic pain and their effect on serum electrolyte (sodium and potassium).

Methods: The patients include 60 diabetic patients of either sex aged 18-65 years diagnosed with neuropathic pain and divided into two groups. The study was prospective open label and observational study. Group 1 was treated with amitriptyline $10 \mathrm{mg}$ once a day while group 2 with pregabalin $75 \mathrm{mg}$ once a day and HRV, serum sodium and serum potassium levels and pain score were recorded; and data of post-treatment at 2 and 4 weeks were compared with pretreatment values (control). All the statistical analysis was performed by using SPSS 20.0 software.

Results: Both the drugs have increased HRV and reduced neuropathic pain intensity after 2 and 4 weeks treatment. The sodium and potassium level were not altered by these drugs. No correlation was observed between HRV and neuropathic pain.

Conclusions: In conclusion, both the amitriptyline and pregabalin have significantly increased HRV and reduced the neuropathic pain intensity; but no correlation was observed between increased HRV and reduced neuropathic pain intensity.

Keywords: Heart rate variability, Amitriptyline, Pregabalin, Neuropathic pain, Electrolytes

\section{INTRODUCTION}

Multiple causes of neurpathic pain (NP) have been described, the commonest being diabetes mellitus. Neuropathic pain (irrespective of the cause) had been demonstrated to affect heart rate variability. Autonomic neuropathy is usually manifested in the patients of diabetes mellitus and too affects heart rate variability. Many studies have shown that patients suffering from cardiovascular disease with low heart rate variability (HRV) have risk for mortality. Heart rate variability
(HRV) is the physiological phenomenon of variation in the time interval between heartbeats. It is measured by the variation in the "RR interval". A high degree of HRV reflects the ability to adapt quickly to physical or psychological demands of the environment as seen in healthy individuals, while lower levels of HRV are associated with cardiac damage, including myocardial infarction, impaired ventricular ejection and sudden cardiac death. Chronic NP involves the affective and evaluative components and associated with abnormality in autonomic nervous system. ${ }^{1,2}$ Patients with neuropathic pain have lower HRV, which can be determined by HRV 
time domain parameter SDNN. ${ }^{3}$ Patients with diabetic neuropathy have also shown altered HRV indices. ${ }^{4}$ Studies have shown that treatment with tricyclic antidepressants including amitriptyline in cases of depression was associated with decrease in HRV. ${ }^{5}$ Pregabalin increases the heart rate variability and thus improves cardiac autonomic functions. Also, amitriptyline affects QT interval resulting in its prolongation; thus may contribute to cardiac morbidity and mortality in long term outcomes.

Drugs like pregabalin, low dose amitriptyline, duloxetine and gabapentin have proved to be beneficial in relieving pain in the patients of neuropathic pain. Studies outside India have shown that low dose amitriptyline and pregabalin produced significant effects on heart rate variability. The data regarding effects of amitriptyline and pregabalin on cardiac autonomic function i.e. effect on HRV in neuropathic patient in India are limited and poorly understood. Thus, present study was conducted to study effect of amitriptyline and pregabalin on HRV and whether HRV is related with alteration in neuropathic pain. Serum sodium and potassium level were also measured to find out any correlation between HRV and sodium and potassium level. The safety (with respect to heart rate variability) of amitriptyline and pregabalin in neuropathic pain was also compared.

\section{METHODS}

\section{Study population}

The subjects/patients were recruited from the medicine outpatient department of tertiary care hospital (New Civil hospital, Government medical college, Surat) with a sample size of 60 diabetic patients, suffering from neuropathic pain. The study period was from Janaury 2017 to June 2018. The study was approved by institutional ethical committee before the commencement of study. Written informed consents were taken from the participants (patients) before their enrollment for study.

\section{Study design}

Our study is a prospective open label, observational study with a follow up period of 4 weeks. The present study includes 60 patients of either sex aged 18-65 years diabetic who have been diagnosed with neuropathic pain. They were further subdivided into 2 groups. Group-1 amitriptyline group with 28 patients (13 males and 15 females) as 2 patients lost to follow up; and group-2 pregabalin group with 27 patients (16 males and 11 females) as 3 patients lost to follow up. The group -1 was treated with amitriptyline (10 $\mathrm{mg}$ once day i.e. OD); while group-2 with pregabalin (75 mg OD). In each group, heart rate variability (ECG), serum sodium and potassium levels and pain score were recorded. Pretreatment value of heart rate variability, serum potassium, serum sodium and pain score of the same patient were served as control. The parameters recorded were compared for pretreatment and posttreatment/follow up at 2 and 4 weeks.

\section{Inclusion criteria}

The inclusion criteria were patients of either sex between the ages of 18-65 years, patients who are giving informed consent, newly diagnosed patients of diabetic neuropathic pain, not exposed to earlier treatment with amitriptyline and pregabalin and undergoing therapy for the duration of minimum 4 weeks.

\section{Exclusion criteria}

The exclusion criteria were patients not giving consent for enrolment in study, patients with cardiovascular disease, patients with history of substance abuse within a year, patients with suicidal tendencies (depression), concurrent major illness or systemic dysfunction involving hepatic and renal system, children, pregnant and lactating women and patients with history of allergy to any of the above medication.

\section{Procedure}

Heart rate variability (HRV) was calculated by root mean square deviation of successive differences between adjacent RR intervals (RMSSD). ECG was recorded for 5 minutes by physiopac digital polygraph software after 20 minutes of rest. The pain was assessed by using an 11 point visual analog scale (VAS; $0-10 \mathrm{~cm}$ ) representing the pain intensity, where 0 represents "no pain" and 10 indicates "unbearable pain." The blood samples of patients were taken to determine the sodium and potassium level before the treatment (pre-treatment) and 2 and 4 weeks after the treatment (post-treatment).

\section{Statistical analysis}

All the statistical analysis was performed by using SPSS 20.0 software. All values obtained were expressed as mean \pm SD. The final statistical analysis was performed by repeated measure analysis of variance (ANOVA) test to find put any significant difference with GreenhouseGeisser correction; followed by post hoc analysis with Bonferroni correction. The $\mathrm{p}<0.05$ was taken as minimal level of significance.

\section{RESULTS}

Amitriptyline has produced statistically significant effect on heart rate variability after 2 weeks $(56.10 \pm 8.54)$ $(\mathrm{p}<0.0001)$ and 4 weeks $\quad(68.989 \pm 10.8) \quad(\mathrm{p}<0.0001)$ treatment as compared to pretreatment values. On pairwise comparison, the effect of amitriptyline on HRV after 4 weeks $(\mathrm{p}<0.0001)$ treatment as compared to 2 weeks $(\mathrm{p}<0.003)$ treatment was statistically significant indicating further increase in HRV (Table 1-2). Pregabalin has also produced statistically significant effect on heart rate variability after 2 weeks $(54.89 \pm 9.06)$ 
$(\mathrm{p}<0.0001)$ and 4 weeks $(69.03 \pm 10.6) \quad(\mathrm{p}<0.0001)$ as compared to pretreatment values. Comparing the effect of pregabalin on HRV between 2 weeks and 4 weeks treatment was statistically significant indicating further increase in HRV (Table 3-4).

Table 1: Effect of amitriptyline on HRV in diabetic patients (estimates).

\begin{tabular}{|c|c|c|c|c|c|}
\hline \multirow{2}{*}{ Heart rate variability } & \multirow{2}{*}{ Mean } & \multirow{2}{*}{ Std. Error } & \multicolumn{2}{|c|}{ 95\% Confidence interval } & \multirow{2}{*}{ P value } \\
\hline & & & Lower bound & Upper bound & \\
\hline Pretreatment & 51.146 & 4.325 & 42.273 & 60.020 & \multirow{3}{*}{$<0.0001$} \\
\hline After 2 weeks & 56.107 & 4.271 & 47.343 & 64.871 & \\
\hline After 4 weeks & 68.989 & 5.405 & 57.898 & 80.080 & \\
\hline
\end{tabular}

Table 2: Effect of amitriptyline on HRV in diabetic patients (pairwise comparisons based on table 1).

\begin{tabular}{|c|c|c|c|c|c|c|}
\hline \multirow{2}{*}{ (I) HRV } & \multirow{2}{*}{ (J) HRV } & \multirow{2}{*}{ Mean difference (I-J) } & \multirow[t]{2}{*}{ Std. Error } & \multirow[t]{2}{*}{ P value } & \multicolumn{2}{|c|}{$\begin{array}{l}95 \% \text { Confidence interval for } \\
\text { difference }^{\mathrm{a}}\end{array}$} \\
\hline & & & & & Lower bound & Upper bound \\
\hline \multirow{2}{*}{$\begin{array}{l}\text { Pre } \\
\text { treat }\end{array}$} & After 2 weeks & $-4.961^{*}$ & 1.730 & 0.008 & -8.511 & -1.410 \\
\hline & After 4 weeks & $-17.843^{*}$ & 4.440 & $<0.0001$ & -26.952 & -8.734 \\
\hline \multirow{2}{*}{$\begin{array}{l}\text { After } 2 \\
\text { weeks }\end{array}$} & Pretreatment & $4.961^{*}$ & 1.730 & 0.008 & 1.410 & 8.511 \\
\hline & After 4 weeks & $-12.882^{*}$ & 3.967 & 0.003 & -21.022 & -4.742 \\
\hline \multirow{2}{*}{$\begin{array}{l}\text { After } 4 \\
\text { weeks }\end{array}$} & Pretreatment & $17.843^{*}$ & 4.440 & $<0.0001$ & 8.734 & 26.952 \\
\hline & After 2 weeks & $12.882^{*}$ & 3.967 & 0.003 & 4.742 & 21.022 \\
\hline
\end{tabular}

Based on estimated marginal means, *the mean difference is significant at the 0.05 level. a. adjustment for multiple comparisons.

Table 3: Effect of pregabalin on HRV in diabetic patients (estimates).

\begin{tabular}{|c|c|c|c|c|c|}
\hline \multirow{2}{*}{ Heart rate variability } & \multirow{2}{*}{ Mean } & \multirow{2}{*}{ Std. Error } & \multicolumn{2}{|c|}{ 95\% Confidence interval } & \multirow{2}{*}{$P$ value } \\
\hline & & & Lower bound & Upper bound & \\
\hline Pretreatment & 50.481 & 4.517 & 41.196 & 59.767 & \multirow{3}{*}{$<0.0001$} \\
\hline After 2 weeks & 54.896 & 4.503 & 45.640 & 64.153 & \\
\hline After 4 weeks & 69.033 & 5.375 & 57.985 & 80.081 & \\
\hline
\end{tabular}

Table 4: Effect of pregabalin on HRV in diabetic patients (pairwise comparisons based on table 3).

\begin{tabular}{|c|c|c|c|c|c|c|}
\hline \multirow[t]{2}{*}{ (I) HRV } & \multirow[t]{2}{*}{ (J) HRV } & \multirow[t]{2}{*}{ Mean difference (I-J) } & \multirow[t]{2}{*}{ Std. Error } & \multirow[t]{2}{*}{$P$ value } & \multicolumn{2}{|c|}{$\begin{array}{l}95 \% \text { Confidence interval for } \\
\text { difference }^{\mathrm{a}}\end{array}$} \\
\hline & & & & & Lower bound & Upper bound \\
\hline \multirow{2}{*}{$\begin{array}{l}\text { Pre } \\
\text { treat }\end{array}$} & After 2 weeks & $-4.415^{*}$ & 0.689 & $<0.0001$ & -5.832 & -2.998 \\
\hline & After 4 weeks & $-18.552^{*}$ & 4.296 & $<0.0001$ & -27.382 & -9.721 \\
\hline \multirow{2}{*}{$\begin{array}{l}\text { After } 2 \\
\text { weeks }\end{array}$} & Pretreatment & $4.415^{*}$ & 0.689 & $<0.0001$ & 2.998 & 5.832 \\
\hline & After 4 weeks & $-14.137^{*}$ & 4.393 & 0.003 & -23.167 & -5.107 \\
\hline \multirow{2}{*}{$\begin{array}{l}\text { After } 4 \\
\text { weeks }\end{array}$} & Pretreatment & $18.552^{*}$ & 4.296 & $<0.0001$ & 9.721 & 27.382 \\
\hline & After 2 weeks & $14.137^{*}$ & 4.393 & 0.003 & 5.107 & 23.167 \\
\hline
\end{tabular}

Based on estimated marginal means, *the mean difference is significant at the 0.05 level, a. adjustment for multiple comparisons: Bonferroni: least significant difference

Table 5: Effect of amitriptyline on neuropathic pain in diabetic patients (estimates).

\begin{tabular}{|c|c|c|c|c|c|}
\hline \multirow{2}{*}{ Pain score } & \multirow{2}{*}{ Mean } & \multirow{2}{*}{ Std. Error } & \multicolumn{2}{|c|}{ 95\% Confidence interval } & \multirow{2}{*}{ P value } \\
\hline & & & Lower bound & Upper bound & \\
\hline Pretreatment & 8.168 & 0.108 & 7.946 & 8.389 & \multirow{3}{*}{$<0.0001$} \\
\hline After 2 weeks & 6.414 & 0.073 & 6.265 & 6.563 & \\
\hline After 4 weeks & 4.175 & 0.106 & 3.958 & 4.392 & \\
\hline
\end{tabular}


Table 6: Effect of amitriptyline on neuropathic pain in diabetic patients (Pairwise comparisons based on table 5).

\begin{tabular}{|c|c|c|c|c|c|c|}
\hline \multirow{2}{*}{$\begin{array}{l}\text { (I) Pain } \\
\text { score }\end{array}$} & \multirow{2}{*}{ (J) Pain score } & \multirow[t]{2}{*}{ Mean difference (I-J) } & \multirow[t]{2}{*}{ Std. Error } & \multirow[t]{2}{*}{ P value } & \multicolumn{2}{|c|}{$\begin{array}{l}95 \% \text { Confidence interval for } \\
\text { difference }^{\mathrm{a}}\end{array}$} \\
\hline & & & & & Lower bound & Upper bound \\
\hline \multirow{2}{*}{$\begin{array}{l}\text { Pre } \\
\text { treat }\end{array}$} & After 2 weeks & $1.754^{*}$ & 0.118 & $<0.0001$ & 1.511 & 1.996 \\
\hline & After 4 weeks & $3.993^{*}$ & 0.150 & $<0.0001$ & 3.685 & 4.301 \\
\hline \multirow{2}{*}{$\begin{array}{l}\text { After } 2 \\
\text { weeks }\end{array}$} & Pretreatment & $-1.754^{*}$ & 0.118 & $<0.0001$ & -1.996 & -1.511 \\
\hline & After 4 weeks & $2.239^{*}$ & 0.113 & $<0.0001$ & 2.008 & 2.471 \\
\hline \multirow{2}{*}{$\begin{array}{l}\text { After } 4 \\
\text { weeks }\end{array}$} & Pretreatment & $-3.993^{*}$ & 0.150 & $<0.0001$ & -4.301 & -3.685 \\
\hline & After 2 weeks & $-2.239^{*}$ & 0.113 & $<0.0001$ & -2.471 & -2.008 \\
\hline
\end{tabular}

Based on estimated marginal means, *the mean difference is significant at the 0.05 level, a. adjustment for multiple comparisons: least significant difference (equivalent to no adjustments).

Table 7: Effect of pregabalin on neuropathic pain in diabetic patients (estimates).

\begin{tabular}{|lllll|}
\hline \multirow{2}{*}{ Pain score } & \multirow{2}{*}{ Mean } & Std. Error & \multicolumn{2}{l|}{$\mathbf{9 5 \% \text { Confidence interval }}$ P value } \\
\hline Pretreatment & 8.407 & 0.074 & 8.256 & 8.559 \\
\hline After 2 weeks & 6.396 & 0.081 & 6.230 & 6.562 \\
\hline After 4 weeks & 3.763 & 0.081 & 3.596 & 3.930 \\
\hline
\end{tabular}

Table 8: Effect of pregabalin on neuropathic pain in diabetic patients (pairwise comparisons based on table 7).

\begin{tabular}{|c|c|c|c|c|c|c|}
\hline \multirow{2}{*}{$\begin{array}{l}\text { (I) Pain } \\
\text { score }\end{array}$} & \multirow{2}{*}{ (J) Pain score } & \multirow{2}{*}{ Mean difference (I-J) } & \multirow[t]{2}{*}{ Std. Error } & \multirow[t]{2}{*}{ P value } & \multicolumn{2}{|c|}{$\begin{array}{l}\text { 95\% Confidence interval for } \\
\text { difference }^{\mathrm{a}}\end{array}$} \\
\hline & & & & & Lower bound & Upper bound \\
\hline \multirow{2}{*}{$\begin{array}{l}\text { Pre } \\
\text { treat }\end{array}$} & After 2 weeks & $2.011^{*}$ & 0.105 & $<0.0001$ & 1.795 & 2.227 \\
\hline & After 4 weeks & $4.644^{*}$ & 0.116 & $<0.0001$ & 4.407 & 4.882 \\
\hline \multirow{2}{*}{$\begin{array}{l}\text { After } 2 \\
\text { weeks }\end{array}$} & Pretreatment & $-2.011^{*}$ & 0.105 & $<0.0001$ & -2.227 & -1.795 \\
\hline & After 4 weeks & $2.633^{*}$ & 0.110 & $<0.0001$ & 2.407 & 2.860 \\
\hline \multirow{2}{*}{$\begin{array}{l}\text { After } 4 \\
\text { weeks }\end{array}$} & Pretreatment & $-4.644^{*}$ & 0.116 & $<0.0001$ & -4.882 & -4.407 \\
\hline & After 2 weeks & $-2.633^{*}$ & 0.110 & $<0.0001$ & -2.860 & -2.407 \\
\hline
\end{tabular}

Based on estimated marginal means, *the mean difference is significant at the 0.05 level, a. adjustment for multiple comparisons:

Bonferroni: least significant difference

Table 9: Effect of amitriptyline on serum sodium and potassium in diabetic patients.

\begin{tabular}{|c|c|c|c|c|c|c|}
\hline \multirow{2}{*}{ Drugs } & \multirow{2}{*}{ Variable } & \multirow{2}{*}{ Mean } & \multirow{2}{*}{ Std. Error } & \multicolumn{2}{|c|}{ 95\% Confidence Interval } & \multirow[b]{2}{*}{$P$ value } \\
\hline & & & & Lower bound & Upper bound & \\
\hline \multirow{3}{*}{$\mathbf{N a}$} & Pretreatment & 140.236 & 0.470 & 139.271 & 141.201 & \multirow{3}{*}{0.562} \\
\hline & After 2 weeks & 140.243 & 0.556 & 139.101 & 141.384 & \\
\hline & After 4 weeks & 140.000 & 0.358 & 139.266 & 140.734 & \\
\hline \multirow{3}{*}{$\mathbf{K}$} & Pretreatment & 4.204 & 0.065 & 4.069 & 4.338 & \multirow{3}{*}{0.816} \\
\hline & After 2 weeks & 4.050 & 0.064 & 3.918 & 4.182 & \\
\hline & After 4 weeks & 4.193 & 0.044 & 4.103 & 4.283 & \\
\hline
\end{tabular}

Amitriptyline has produced reduction in neuropathic pain intensity as observed on VAS after 2 and 4 weeks treatment as compared to pretreatment values. The reduction in pain was statistically significant $(\mathrm{p}<0.0001)$. On pair-wise comparison, the effect of amitriptyline on pain after 4 weeks treatment as compared to 2 weeks treatment was also statistically significant (Table 5-6). The patients treated with pregabalin have shown reduced neuropathic pain intensity which was statistically significant $(\mathrm{p}<0.0001)$. On pair-wise comparison, there was further reduction in pain intensity after 4 weeks treatment as compared to 2 weeks treatment. This reduction in pain intensity was also statistically significant (Table 7-8). There was no significant difference on sodium and potassium level after 2 and 4 weeks treatment with amitriptyline as compared to pretreatment values. The pair-wise analysis was not applied as the serum values were within normal range (Table 9). Similaly, no significant difference was observed on sodium and potassium level after 2 and 4 
weeks treatment with pregabalin as compared to pretreatment values. The serum values were within normal range, therefore, pair-wise analysis was not applied (Table 10).

Table 10: Effect of pregabalin on serum sodium and potassium in diabetic patients.

\begin{tabular}{|c|c|c|c|c|c|c|}
\hline \multirow{2}{*}{ Drugs } & \multirow{2}{*}{ Variable } & \multirow{2}{*}{ Mean } & \multirow{2}{*}{ Std. Error } & \multicolumn{2}{|c|}{ 95\% Confidence Interval } & \multirow[b]{2}{*}{$P$ value } \\
\hline & & & & Lower bound & Upper bound & \\
\hline \multirow{3}{*}{$\mathbf{N a}$} & Pretreatment & 140.159 & 0.482 & 139.169 & 141.149 & \multirow{3}{*}{0.063} \\
\hline & After 2 weeks & 140.107 & 0.481 & 139.119 & 141.096 & \\
\hline & After 4 weeks & 141.430 & 0.364 & 140.681 & 142.178 & \\
\hline \multirow{3}{*}{ K } & Pretreatment & 4.063 & .061 & 3.937 & 4.189 & \multirow{3}{*}{0.092} \\
\hline & After 2 weeks & 4.048 & .059 & 3.927 & 4.170 & \\
\hline & After 4 weeks & 4.196 & .045 & 4.103 & 4.290 & \\
\hline
\end{tabular}

In the present study, no difference was observed between effect of amitriptyline and pregabalin on HRV in diabetic neuropathy patients indicating their similar effect on HRV. Also on anlaysis, no co-relation was observed between HRV and neuropathic pain in diabetic patients (data not shown).

\section{DISCUSSION}

Increased risk of sudden cardiac death in patients with ischaemic heart disease and heart failure was associated with low HRV as shown by various studies. ${ }^{4,6}$ Amitriptyline has produced statistically significant effect on heart rate variability (HRV) after 2 and 4 weeks treatment as compared to pretreatment values in diabetic patients. On the contrary, when used in cases of depression, amitriptyline was associated with decrease in HRV. ${ }^{5}$ Effect of pregabalin on HRV was similar to amitriptyline as above. Patients with neuropathic pain have lower HRV. ${ }^{3}$ Patients with diabetic neuropathy have shown altered HRV indices. ${ }^{6}$ Pregabalin increases the heart rate variability; and thus improves cardiac autonomic functions. Similar results were obtained in earlier studies. ${ }^{7,8}$ Jiang et al have also demonstrated the improvement in HRV after pregabalin treatment for 4 week in patients of diabetic neuropathy. ${ }^{9}$

The improvement of HRV was not correlated with reduction in pain intensity in the present study. However, in another study assessment of pain was done by multidimensional pain assessment tool i.e. short form McGill pain questionnaire (SF-MPQ) than the singledimensional assessment tool (VAS). In this study, HRV positively correlated with SF-MPQ scores in patients after abdominal surgery. Amitriptyline has produced significant reduction in neuropathic pain intensity as observed on VAS after 2 and 4 weeks treatment as compared to pretreatment values. Another study has shown improvement of pain by amitriptyline after 4 weeks of treatment though improvement was slow; but adverse effects were more (sedation was common). ${ }^{10}$ The study by Kaur et al have shown that amitriptyline was effective in diabetic neuropathic pain without significant side effect. ${ }^{11}$ In their study also, pain relief showed $>50 \%$ improvement of pain score but complete pain relief was not observed.
The possible mechanism of improved HRV by pregabalin may be due to reduced release of neurotransmitters (glutamate, noradrenaline, 5-HT, dopamine, and substance P) from the presynaptic neurones, leading to reduced sympathetic activity and augmented parasympathetic activity; thus produce improvement in HRV apart from increased GABA level. By similar neurotransmitter mechanism, it produces relief in neuropathic pain. ${ }^{12-15} \mathrm{P}$ Pain relief due to pregabalin may also be associated with activation of $\mathrm{K}_{\mathrm{ATP}}$ channels. ${ }^{16}$ Devi et al have shown significant reduction in pain score by pregabalin. ${ }^{17}$ In their study, dose was titrated based on response of the patients to pain while in our study the dose of pregabalin was fixed (75 $\mathrm{mg}$ once a day) on safety concern. Intensity of pain was significantly reduced but no complete pain relief; possibly due to noncompliance or uncontrolled diabetes or use of lower dose of pregabalin used in our study (75 $\mathrm{mg}$ OD) as compared to other studies (75 $\mathrm{mg}$ to $150 \mathrm{mg}$ twice a day); and assessment of pain by multidimensional pain assessment tool i.e. short form McGill pain questionnaire (SF-MPQ) than the single-dimensional assessment tool (VAS). Chang et al have shown positive correlation between HRV and postoperative pain with SF-MPQ scores in patients after abdominal surgery. ${ }^{18}$ There was no significant difference on sodium and potassium level after 2 and 4 weeks treatment with these drugs and no study has shown alteration in sodium or potassium level by these drugs. Heart rate variability analysis can easily be applied for surveillance of diabetic (post-infarction) patients to prevent sudden death due to cardiac problems.

\section{Limitations}

The limitation of the study was small sample size as few patients lost to follow up and many patient were excluded based on exclusion criteria. The further study may be conducted with bigger sample size.

\section{CONCLUSION}

In conclusion, patients were given treatment and followed up after 2 weeks and 4 weeks. Both the amitriptyline (10 $\mathrm{mg}$ OD) and pregabalin (75 mg OD) have significantly increased $\mathrm{HRV}$ and significantly reduced the pain intensity but no correlation was observed between 
increased HRV and reduced pain intensity. There was no significant change in serum sodium and potassium levels by amitriptyline and pregabalin. In the present study, low dose of these drugs were used; and these doses were safe as no significant adverse effect was observed. Based on our study, both amitriptyline and pregablin can safely be used in the lower doses for the treatment of diabetic neuropathic pain. However, further studies are needed with other drugs used for neuropathic pain and longer duration of treatment and follow up to ascertain maximum efficacy.

\section{ACKNOWLEDGEMENTS}

The authors would like to thank all the staff, department of pharmacology and general medicine, government medical college, Surat for their constant valuable support and suggestions to successfully complete this study

\section{Funding: No funding sources}

Conflict of interest: None declared

Ethical approval: The study was approved by the Institutional Ethics Committee

\section{REFERENCES}

1. Garland EL. Pain processing in the human nervous system. a selective review of nociceptive and biobehavioral pathways. Clin Office Pract. 2012; 39(3):561-71.

2. Bennett MI. Theories, history and current taxonomy. In: Neuropathic pain. Newzeland: Elsevier;2010.

3. Karri J, Zhang L, Li S, Chen Y-T, Stampas A, Li S. Heart Rate Variability: A Novel modality for diagnosing neuropathic pain after spinal cord injury. Front Physiol. 2017; 8:495.

4. Van Ravenswaaij-Arts C, Kollée L, Hopman J, Stoelinga G, Van Geijn H. Heart rate variability. Ann Intern Med. 1993;15;118(6):436-47.

5. Rechlin $\mathrm{T}$. The effect of amitriptyline, doxepin, fluvoxamine, and paroxetine treatment on heart rate variability. J Clin Psychopharmacol. 1994;14(6):3925.

6. Vinik A, Maser R, Mitchell B, Freeman R. Diabetic autonomic neuropathy. Diabetes Care. 2003;26(5): 1553-79.

7. Gilron I. Gabapentin and pregabalin for chronic neuropathic and early postsurgical pain: Current evidence and future directions. Curr Opinion Anaesthesiol. 2007;20(5):456-72.

8. Ermis N, Gullu H, Caliskan M, Unsal A, Kulaksizoglu M, Muderrisoglu H. Gabapentin therapy improves heart rate variability in diabetic patients with peripheral neuropathy. J Diab Complicat. 2010;24(4):229-33.
9. Jiang W, Ladd S, Martsberger C, Feinglos M, Spratt SE, Kuchibhatla M, et al. Effects of pregabalin on heart rate variability in patients with painful diabetic neuropathy. J Clin Psychopharmacol. 2011;31(2): 207-13.

10. Chakrabarty S, Das A, Ganguly A. A prospective, randomised, comparative study of efficacy and safety of pregabalin, duloxetine and amitriptyline in patients of painful diabetic neuropathy in a tertiary care teaching hospital in rural Bengal. J Evolution Med Dent Sci. 2016;5(35):2025-9.

11. Kaur H, Hota D, Bhansali A, Dutta P, Bansal D, Chakrabarti A. A comparative evaluation of amitriptyline and duloxetine in painful diabetic neuropathy: A randomized, double-blind, cross-over clinical trial. Diab Care. 2011;34(4):818-22.

12. Baidya DK, Agarwal A, Khanna P, Arora MK. Pregabalin in acute and chronic pain. J Anaesthesiol Clin Pharmacol. 2011;27:307-14.

13. Fink K, Meder W, Dooley DJ, Göthert M. Inhibition of neuronal $\mathrm{Ca}^{2+}$ influx by gabapentin and subsequent reduction of neurotransmitter release from rat neocortical slices. Br J Pharmacol. 2000; 130(4):900-6.

14. Fehrenbacher JC, Taylor CP, Vasko MR. Pregabalin and gabapentin reduce release of substance $P$ and CGRP from rat spinal tissues only after inflammation or activation of protein kinase C. Pain. 2003; 105(2):131-41.

15. Sills GJ. The mechanisms of action of gabapentin and pregabalin. Curr Opinion Pharmacol. 2006; (1): 108-13.

16. Kweon TD, Kim JY, Kwon IW, Choi JB, Lee YW. Participation of K(ATP) Channels in the Antinociceptive Effect of Pregabalin in Rat Formalin Test. Korean J Pain. 2011;24:131-6.

17. Devi P, Madhu K, Ganapathy B, Sarma G, John L, Kulkarni C. Evaluation of efficacy and safety of gabapentin, duloxetine, and pregabalin in patients with painful diabetic peripheral neuropathy. Indian J Pharmacol. 2012;44:51-6.

18. Chang M, Tsay J. Relationships between pain intensity and heart rate variability in patients after abdominal surgery: a Pilot Study. Chinese Med J. 2012;125(11):196.

Cite this article as: Srivastava R, Kantharia ND. Effect of amitriptyline and pregabalin on heart rate variability and electrolytes in neurotrophic pain in diabetic patients. Int J Basic Clin Pharmacol 2022;11:52-7. 